\title{
A VIOLÊNCIA CONTRA A MULHER RESSIGNIFICADA EM AMBIENTES CIBERNÉTICOS: \\ UMA BREVE ANÁLISE DO ROMANCE MULHERES EMPILHADAS, DE PATRÍCIA MELO
}

\author{
VIOLENCE AGAINST WOMEN RESIGNIFIED IN CYBERNETIC \\ ENVIRONMENTS: \\ A BRIEF ANALYSIS OF THE ROMANCE MULHERES EMPILHADAS, BY \\ PATRÍCIA MELO
}

DOI 10.20873/uft2179-3948.2021v12n1p152-171

Natália Barbosa Gomes Vago ${ }^{1}$

\begin{abstract}
Resumo: Este ensaio pretende analisar a violência contra a mulher ressignificada por meio da internet no romance Mulheres Empilhadas, de Patrícia Melo, cujos universo temático e estratégias discursivas mostram o que é ser mulher vítima de violência no Brasil. O objetivo é apontar de que maneira a violência contra a mulher extrapola os limites físicos e sexuais, estendendo-se aos ambientes cibernéticos, de modo que se torne instrumento de vingança, perversão e formação de comportamentos masculinos, de quem os atos contra a mulher, vistos pela ótica de uma narradora sem nome, pode retratar uma nova realidade da violência no Brasil.
\end{abstract}

Palavras-chave: pornografia; vingança; internet; violência; mulher.

\begin{abstract}
This essay intends to analyze the violence against women resignified through the internet in the novel Mulheres Empilhadas, by Patrícia Melo, whose thematic universe and discursive strategies show what it is to be a woman victim of violence in Brazil. The objective is to point out how violence against women goes beyond physical and sexual limits, extending to cybernetic environments, so that it becomes an instrument of revenge, perversion and formation of male behavior, whose acts against women, seen by In the view of an unnamed narrator, it can portray a new reality of violence in Brazil.
\end{abstract}

Keywords: pornography; revenge; Internet; violence; women.

\footnotetext{
1 Natália Barbosa Gomes Vago é licenciada em Letras pelo Centro Universitário Geraldo Di Biasi, especialista em Literatura Brasileira pela Faculdade Integrada de Jacarepaguá e mestranda em Estudos Literários pela Universidade Federal Fluminense. Atua como professora da educação básica na Rede Municipal de Volta Redonda e na Rede Estadual do Rio de Janeiro. É tutora presencial do Consórcio CEDERJ. Email: nataliabhomesvr@yahoo.com.br
} 


\section{Introdução}

Durante um longo período da história, a mulher sempre ocupou papéis muito bem definidos: mãe, esposa, dona de casa. Entretanto, com o passar do tempo, foi ocupando cada vez mais espaço na sociedade e assumindo postos que, até então, eram absolutamente masculinos. A elas, foi dado direito ao voto, acesso às universidades e ao mercado de trabalho, até então, direitos masculinos. Entretanto, quando se trata de relacionamentos, principalmente os amorosos, o homem ainda se acha no direito de tratar a mulher como quer, mesmo que as leis e a sociedade digam o contrário.

Por muito tempo, as mulheres foram caladas pela vergonha, pela família e pelas instituições religiosas e sociais. E, por isso, durante anos, foram agredidas, estupradas, coagidas e mortas, não somente nas ruas, mas também dentro de suas casas, vítimas de um sistema patriarcal, alicerçado numa suposta tradição que ainda insiste em existir. Caladas durante muito tempo, decidiram dar um basta e foram para as ruas. O movimento feminista surge como um alento. Os casos de violência, até então mantidos em segredo, começam a vir à tona, pois não se pode negar a violência sistemática a que a mulher foi submetida durante muitos anos. Muitas vezes, o agressor foi protegido pela lei, principalmente pelos crimes que definidos como passionais ou em defesa da honra.

Com os casos de feminicídio cada vez mais evidentes, houve a criação de leis e mecanismos que visavam defender a mulher. Essas políticas ganham mais força na segunda metade da década de 80, quando foram criadas as primeiras Delegacias de Defesa da Mulher (DMM). Entretanto, as políticas criadas e mesmo a sanção da Lei Maria da Penha, sancionada em 2006, conseguiram inibir os agressores que consideram as mulheres como suas propriedades, tolhendo a liberdade, os desejos e, muitas vezes, ceifando-lhes a vida. É nesse sentido que o feminicídio, segundo Saffioti (1999, p. 84), está localizado entre a preservação da integridade da mulher e até onde ela está disposta a se submeter ao companheiro para que a relação dê certo.

O homem não reconhece a mulher como ser humano, tratando-a como um objeto. E, se é considerada um objeto, o agressor acha-se no direito de fazer com ela o que bem entender. Sobre essa relação de posse, Benhabib e Cornell afirmam que “(...) o reconhecimento da integridade do corpo da mulher (...) violência e sexo forçado na vida doméstica estão longe de ser universalmente aceitos nas democracias ocidentais.” (1987, p. 17) 
Esse tipo de relação doentia e a noção de que o amor pode justificar o crime, aliados à sensação de impunidade levam ao aumento gigantesco dos casos de feminicídio, agressões, estupro e violência doméstica no Brasil, os quais estampam a capa de jornais e ganham destaque na internet todos os dias, inclusive no Acre, onde a história de Mulheres Empilhadas se pass. Esse estado ocupa o primeiro lugar no ranking de feminicídios no país. Segundo pesquisas, a cada cem mil mulheres, sete são assassinadas única e exclusivamente por serem mulheres, ou seja, são mortas por questões de gênero. A questão em si serve como alerta não só para a situação da mulher no país, mas também para o desenvolvimento de uma história que mistura o mundo dos sonhos, da ficção e fatos na formação de um universo que, embora distópico, está cada vez mais próximo de realidade.

São cada vez mais evidentes na mídia os casos de feminicídio. E é esse assunto que Patrícia Melo aborda no livro Mulheres Empilhadas. Autora conhecida e premiada por livros como O Matador, escrito em 1995, e Inferno, publicado em 2000 e ganhador do prêmio Jabuti em 2001, em que aborda a violência num universo predominantemente masculino, Patrícia Melo se debruça agora, pela primeira vez, numa temática feminina: a violência contra a mulher. Tema tão recorrente em jornais, revistas e mídias diversas, no romance o assunto é tratado de maneira visceral. Não há romantização ou redenção do agressor. No livro, mulheres são assassinadas, em grande parte das vezes, por homens conhecidos e a quem amaram e em quem confiaram. Essas vítimas estavam, literalmente, dormindo com o inimigo.

O livro, narrado em primeira pessoa, escrito predominantemente no pretérito perfeito, conta a história de uma jovem advogada que, após ser agredida pelo namorado e mergulhada nas lembranças de ter presenciado a mãe ser morta pelo próprio marido e pai da menina, mudase para o Acre, onde acompanha um mutirão de julgamentos de feminicídio. A protagonista poderia ser descrita como: “(...) o orgulho de se saber livre, independente, autoabastecida, autorizada a encarar os homens quase de igual para igual, condenada a não poder descansar no papel tradicional de mulher protegida" (PRAVAZ, 1981, p. 61)

A narrativa torna-se ainda mais cruel conforme o leitor percebe que a impunidade é ainda maior se o agressor for branco e rico. O mesmo vale para a investigação, uma vez que Melo afirma "Com minha mãe não puderam fazer isso por uma razão muito simples. Ela era branca. E não era pobre.” (2019.p. 16). Ou seja, o caso da mãe da protagonista teve uma resolução, pois pertencia a uma classe privilegiada dentro de uma realidade muito surreal.

A estrutura do livro é dividida em três partes, que são intercaladas: um índice numérico apresenta casos reais retirados das páginas dos jornais; o índice alfabético retrata a história 
central da advogada paulista, entre dilemas e descobertas; e o índice de alfabeto grego, do alfa a etá, narra os encontros da protagonista com uma tribo de guerreiras amazônicas em delírios proporcionados por uma beberagem indígena, inspirados na lenda das Icamiabas, guerreiras que lutam contra os homens. Nesse mundo paralelo, formam um grupo composto apenas por mulheres que perseguem, julgam e matam os criminosos que escapam da justiça na vida real.

Ao longo da narrativa, de maneira crua e quase rude, o destino das mulheres, crescidas ou ainda crianças, de todas as cores e tamanhos, credos, idades, classes sociais e níveis de escolaridade, é mostrado. Todas são vítimas de homens, assassinadas na maioria das vezes por conhecidos - pais, tios, avôs, maridos, namorados, ex-maridos. A violência doméstica e o feminicídio não são revestidos de nenhum tipo de preconceito e atingem qualquer classe social:

Profissão do acusado: Militar. Eletricista. Servente de pedreiro. Lavrador. Funcionário público. Estudante. Matar mulheres é um crime democrático, pode-se dizer. Eu fazia minhas próprias tabelas que, no futuro, transformariam aquelas estatísticas em mais estatísticas. Grau de instrução do acusado: Semianalfabeto. Superior completo. Analfabeto. Nível universitário. Grau de relação com a vítima: Marido. Namorado. Amante. Ex-amante. Irmão. Cunhado. Padrasto. Em apenas cinco casos, o assassino não conhecia a vítima. (2019. p.17)

A violência que atinge mulheres há séculos passa a ter novos contornos conforme os avanços tecnológicos acontecem e está presente na mídia, na literatura e, principalmente, na internet, sendo esse último recurso utilizado para ressignificar a violência de gênero. E é isso que esse ensaio pretende analisar.

\section{A Pornografia}

Patrícia Melo expõe, em Mulheres Empilhadas, uma leitura desencantada da realidade da mulher no Brasil contemporâneo, deixando claro que o feminicídio é democrático, pois não escolhe cor, religião, grau de instrução ou classe social. A representação ficcional da violência doméstica se dá em diálogo com notícias retiradas dos jornais e a associação entre prosa e jornalismo dão um tom ainda mais verossímil à história, não deixando que a memória dessas mulheres caia no esquecimento. Sobre isso, Lúcia Helena Vianna afirma:

Nas narrativas femininas, em especial nos contos de escritoras brasileiras, a que desejo dar relevo, recordações e reminiscências, lembranças e esquecimentos manifestam ora explicitados ora de forma escamoteada, sob diferentes ardis estratégicos - a permanente intervenção de material memorialístico na matéria narrada. (2019) 
A história traz, pela perspectiva feminina, as várias formas de violência a que as mulheres estão sujeitas. O livro descortina, também, uma realidade ainda mais cruel: a das mulheres indígenas (tema de bastante relevância para inserir as Icamiabas). Se a justiça quase não é feita para as todas as outras, para a índia é completamente inexistente. E isso fica claro em uma conversa entre Carla e a protagonista:

O que a impressionou de verdade foi o fato de eu ter dado uma prensa no marido de Naia.

- A coisa é muito mais complexa do que você pensa - disse ela. - Esses povos têm suas próprias regulamentações, suas próprias maneiras de resolver os abusos na comunidade.

- Ela está grávida - insisti. - E se abortar, por causa de uma surra?

- Muitas apanham. Há muito machismo no mundo indígena. Mas você agiu como se estivesse em Cruzeiro do Sul. Ou São Paulo. Você não sabe nada sobre os indígenas.

- O que você acha que eu deveria ter feito? Ficado quieta?

- O que posso dizer com segurança é que a lei Maria da Penha não resolve nada ali. Ela serve para mulher branca. Da cidade. Para proteger Naia, temos que falar de demarcação de territórios indígenas. Quanto mais vulnerável uma comunidade, quanto mais desestruturada, mais a mulher indígena sofre esse tipo de violência, que é, na verdade, um efeito colateral da forma como os indígenas são tratados no Brasil. Veja, não estou criticando você. Também já interferi em situações semelhantes. Sabe o que a mulher agredida me disse? "Deixa ele me bater. O corpo é meu. E ele gosta." (MELO, 2019, p. 152-153)

A mulher indígena (assim como a branca e a negra) não é dona de seus desejos e vontades. $\mathrm{Na}$ verdade, ela sequer é dona do próprio corpo. É como Benhabib e Cornell afirmam “ (...) a concepção pública do eu como igual e abstrato portador de direitos do qual provém o liberalismo é prejudicada pela desigualdade e a dominação que permeia a identidade privada desse eu como sujeito dotado de gênero." (1987, p.17)

Essa dominação fica clara na obra. É o que acontece com a mãe da protagonista, pois é assassinada pelo ex-marido que decide como sua vida deve terminar. A personagem principal, após ser agredida pelo namorado, temendo ter o mesmo destino da mãe, libera-se das amarras, abrindo mão do relacionamento (abusivo, diga-se de passagem) e segue um outro caminho, refugiando-se no Acre, onde a sua jornada começa.

É ali, no meio da floresta amazônica e entre tantos casos de violência contra a mulher que a personagem se redescobre e se cura das mágoas e feridas do passado. E, nesse reencontro consigo mesma, vai lutar contra a impunidade, viver um novo relacionamento e procurar dar voz e vez às mulheres que foram mortas e agredidas.

Assim sendo, o fio condutor da narrativa de Mulheres Empilhadas cumpre uma série de etapas até que a protagonista consiga lidar com os traumas sofridos, pois aprende a se 
familiarizar com os segredos e as dificuldades do novo ambiente em que está inserida individual e socialmente, tornando-se capaz de ter experiências que a integram ao novo local e tornar-se produtiva, levando a uma renovação de sua alma e a uma mudança de atitudes em relação a si mesma.

O caminho percorrido pela protagonista não é fácil, mas é passível de ser trilhado. E, durante esse percurso, é possível perceber a solidariedade feminina, uma vez que a narradora não só ajuda outras mulheres, mas também é ajudada. É nesse universo que a protagonista não só termina a sua jornada com profundas modificações, mas também pronta para um recomeço e disposta a dividir a sua experiência como forma de ajudar outras mulheres, como fica claro ao final do livro:

- Esse cara que está esperando você lá fora... o Amir... ele foi meu namorado... falei.

Ela me olhou surpresa. Sorriu, mais espantada do que curiosa. - Cuidado -

- Ele me agrediu fisicamente.

Abri meu celular e mostrei a minha página.

- Entrei com um processo contra ele - continuei. - Se quiser mais detalhes basta visitar este site.

Ela continuou me olhando, creio que avaliava se devia ou não confiar em mim. Por fim, pegou meu celular, olhou-o por um breve instante e depois me devolveu.

- Achei que você devia saber - falei, antes de sair do banheiro. (MELO, 2019, p.233)

A ligação entre ficção e realidade na obra mostra os novos pactos de escrita que a produção de Melo estabelece como um registro da violência contra a mulher no Brasil, dando destaque às mulheres assassinadas e deixando claro que são muito mais que estatística, enfatizando a presença de elementos da vida real, misturados à ficção e à fantasia que, com o auxílio da protagonista-narradora, conduzem a uma impactante denúncia do feminicídio no Brasil, através de uma narrativa que destaca a violência bruta e a crítica aguda às formas de organização de um mundo machista.

A história traz, pela perspectiva feminina, as várias formas de violência a que as mulheres estão sujeitas, seja ela física, sexual, moral ou social. A violência contra a mulher é banalizada e negligenciada, o que faz com que uma reflexão sobre o tema seja estimulada. Para além de casos de violência já citados, obra também se debruça sobre um outro tipo de violência que está diretamente ligada à pornografia e à sua propagação em um ambiente relativamente novo: o cibernético.

Sexo vende. Isso é uma grande verdade. Músicas de cunho sexual, livros que contêm cenas eróticas, revistas de homens e mulheres nuas, prostituição, objetificação de corpos para 
conseguir audiência e, por fim, a pornografia que sempre foi vista como um tema que gera bastante controvérsia.

A pornografia foi criada com o propósito de contestar e criticar autoridades políticas e religiosas e, somente no final do século XVIII, torna-se instrumento de prazer sexual. A grande questão é o papel que a mulher ocupa dentro do mundo pornográfico e a maneira como a pornografia pode influenciar, incitar e até ser uma forma de violência contra a mulher.

De acordo com o Feminismo, a pornografia é a materialização do patriarcado, pois objetifica a mulher e incita à violência, principalmente na indústria do audiovisual. Se até meados dos anos noventa, o acesso à pornografia era mais difícil, o advento da internet deixou toda a população a um clique de todos os tipos de sexo disponíveis, inclusive aqueles que são considerados tabus, como incesto e zoofilia.

As narrativas pornográficas se popularizaram ao redor do mundo, nas mais diversas culturas, entre público de idade variada, mas uma coisa é comum: setenta por cento do público é formado por homens, o que se reflete dentro da indústria da pornografia, pois a maioria esmagadora dos trabalhadores da área é masculina. Nota-se, então que, à semelhança do que acontecia em livros escritos por homens, a mulher que aparece nos filmes pornôs nada mais é que a projeção que o homem faz dela, ou seja, são homens fazendo filmes para outros homens em que a figura feminina aparece submissa, moldada pelo olhar e interpretação masculinos daquilo que eles julgam que é a forma correta de fazer a mulher sentir prazer, o que é o corpo ideal e o que é o comportamento aceitável.

É comum que essas narrativas sexuais sejam recheadas de tapas, puxões de cabelo e sexo violento, colocando a mulher em uma posição inferior. Vende-se, também, a imagem perfeita de uma mulher jovem, bonita e sem nenhum pelo no corpo, assim como os fetiches (ninfetas, MILF's, professoras, enfermeiras etc). Há, ainda, a questão de filmes que extrapolam o que é considerado sexo tradicional e partem para o que é chamado de sexo Snuff, em que estupro, agressões e mortes servem como forma de dar prazer ao espectador.

Sobre isso, Bourdieu ressalta que:

Se a relação sexual se mostra como uma relação social de dominação, é porque ela está constituída através do princípio de divisão fundamental entre o masculino, ativo, e o feminino, passivo, e (...) organiza, expressa e organiza o desejo masculino como desejo de posse, como dominação erotizada e o desejo feminino como desejo da dominação masculina, como subordinação erotizada, ou mesmo, em última instância, como reconhecimento erotizado da dominação. (2007, p. 31) 
Dito isso, fica claro que, no mundo pornográfico, quase sempre, a única forma da mulher sentir prazer é sendo dominada. Neste ensaio, analisam-se duas formas de pornografia e como se refletem na vida de mulheres reais: a pornografia de vingança e o snuff.

\section{Ciberviolência contra a mulher: a pornografia de vingança}

É inegável que a criação da internet trouxe inúmeras vantagens para a sociedade. Entretanto, para todo bônus, quase sempre há um ônus. E o preço a ser pago é que proporcionou um crescimento desenfreado da propagação das informações e isso tem redesenhado o consumo de pornografia no mundo.

A sociedade, permanentemente ligada por meio da internet, também foi redefinida no momento em que os meios de comunicação virtuais alcançaram o protagonismo. E as formas de violência contra a mulher também se adaptaram: mulheres são assediadas, aliciadas e ameaçadas através de redes sociais; vídeos íntimos são vazados; mulheres têm suas vidas expostas e destruídas. Se o que é divulgado for algo que denigre a honra de terceiros, a vítima terá a sua dignidade violada diante de milhares de pessoas. E, por conta disso, perde o emprego, precisa mudar de cidade, sofre ameaça e assédio e sua vida é colocada em suspenso.

As mulheres compõem um grupo ainda mais suscetível a sofrer com os efeitos desse tipo de crime. O termo porn revenge surgiu nos Estados Unidos. Em tradução literal, significa pornografia de vingança ou de revanche. Isso acontece quando um ex-companheiro (a) divulga fotos ou vídeos íntimos sem o consentimento da vítima. É uma forma de denegrir e desmoralizar. É muito mais comum que mulheres sofram com esse tipo de vingança e, muitas vezes, o material divulgado é coletado sem o conhecimento da vítima. É uma forma de punir a mulher que se recusa a manter um relacionamento ou de se submeter ao homem. Vitória Buzzi fala sobre isso:

Dentro desta lógica, a pornografia de vingança aparece como um mecanismo contemporâneo de manutenção da ordem. O discurso não possui nada de inovador: é a punição da mulher que nega ou subverte o papel social que lhe foi imposto. $O$ método, no entanto, adaptou-se às novas formas de realizar (e dar publicidade) a humilhação social. As redes sociais podem ser também usadas como instrumento de controle das mulheres. $(2015$, p.12)

É exatamente o que acontece com a protagonista de Mulheres Empilhadas, que, ao não reatar o namoro com Amir, torna-se vítima da pornografia de vingança:

E então Denise me contou. Ela estava realmente chocada: o escritório recebera alguns vídeos com imagens minhas. Íntimas. Eu nua. Eu fazendo sexo.

Mesmo antes de vê-los, eu sabia que só podia ser coisa de Amir. 
- Os americanos até já têm nome para essa prática: revenge porn - explicou Denise. (MELO, 2019, p.154-155)

No caso da protagonista, à exceção de uma foto, todas as imagens e vídeos foram feitos sem o seu conhecimento:

Só me lembro de estar na varanda de casa vendo toda a merda que Denise me encaminhou. Numa das fotos eu estava sentada no vaso sanitário, nua, cortando as unhas do pé direito. Sem calcinha. De todas, essa era a única que fora feita com meu consentimento. Lembro até do que Amir disse naquele momento. Que eu era linda até na privada. Até fazendo cocô. Até menstruada. As outras foram feitas sem minha anuência. Cenas da gente transando. Como ele gravara aquilo sem que eu percebesse? Num outro vídeo, eu aparecia tomando banho, lavando minha bunda. Inacreditável. (MELO, 2019, p.155)

A personagem-narradora deixa claro que não é necessário sofrer a violência pessoalmente (embora a protagonista tenha sido vítima duas vezes) para saber os efeitos que causa na vítima. Não é difícil imaginar todos os danos que o vazamento de fotos ou vídeos íntimos pode causar à imagem, privacidade e moral:

\begin{abstract}
Mais tarde descobri que Amir também enviara as fotos para um site que permitia upload anônimo de material pornográfico. As legendas conseguiam ser ainda piores que as imagens: "Advogada criminal, moderna, sem preconceitos. Adoro sexo grupal." O pior de tudo foi ele ter publicado também o número do meu celular. As mensagens não paravam de pipocar. Vou chupar você todinha. Gostosa. Putinha linda. Vem aqui na minha casa. Você gosta também de dar o cu? Vem chupar a minha rola. (2015, p.155-156)
\end{abstract}

Nesse momento, a protagonista se depara com o pior do ser humano, pois, ao não se submeter ao ex-namorado, percebe que, já que ele não conseguira puni-la fisicamente, pretendia feri-la de outra forma:

De repente, ali mesmo, numa súbita ânsia de vômito, tive a total compreensão do que estava acontecendo. Eu estava sendo queimada na fogueira. Como uma bruxa. Amir, o canalha, que não tinha conseguido me matar fisicamente, tentava me queimar na fogueira virtual. (MELO, 2019, p.156)

Quando se analisa a situação de maneira fria, parece que a conscientização poderia ser de grande ajuda para resolver o problema, pois, a partir do momento em que se humaniza a figura feminina, mostrando que está além de um corpo que serve para proporcionar prazer, seria coerente que esses tipos de crimes deixassem de ocorrer. Entretanto, apenas educar as pessoas não impede que crimes continuem acontecendo, por isso, tonou-se necessária a criminalização 
de tais práticas. Exemplo disso é um emblemático caso envolvendo uma atriz famosa que, em 2012, teve fotos íntimas vazadas após não ceder a uma chantagem. Por ser uma pessoa pública, o caso teve muita exposição, levando à criação da Lei nº 12.737 , de 30 de novembro de 2012, sancionada pela então presidente, Dilma Rousseff. Essa lei torna crime a invasão de computadores ou quaisquer aparelhos eletrônicos com finalidades ilícitas.

Entretanto, ainda que a pornografia de vingança aconteça em ambientes virtuais, a lei não era muito específica para esse tipo de caso. Somente em 2018, a lei no 13.718/18 tornou crime a divulgação de foto, vídeo ou cena de sexo, nudez ou pornografia sem o consentimento da vítima:

\begin{abstract}
Divulgação de cena de estupro ou de cena de estupro de vulnerável, de cena de sexo ou de pornografia

ART. 218C - Oferecer, trocar, disponibilizar, transmitir, vender ou expor à venda, distribuir, publicar ou divulgar, por qualquer meio - inclusive por meio de comunicação de massa ou sistema de informática ou telemática -, fotografia, vídeo ou outro registro audiovisual que contenha cena de estupro ou de estupro de vulnerável ou que faça apologia ou induza a sua prática, ou, sem o consentimento da vítima, cena de sexo, nudez ou pornografia:

Pena - reclusão, de 1 (um) a 5 (cinco) anos, se o fato não constitui crime mais grave. Aumento de pena

$\S 1^{\circ}$ A pena é aumentada de $1 / 3$ (um terço) a $2 / 3$ (dois terços) se o crime é praticado por agente que mantém ou tenha mantido relação íntima de afeto com a vítima ou com o fim de vingança ou humilhação. (2018)
\end{abstract}

A criação dessas leis surgiu em resposta aos anseios da sociedade e, principalmente, de mulheres que não suportam mais serem vítimas de violência dentro e fora de suas casas e, até mesmo no mundo virtual. A lei de 2018 mostra-se ainda mais valiosa porque criminaliza determinadas ações que não constavam na Lei Carolina Dieckmann: a divulgação de imagens com conteúdo sexual.

\title{
2.1.Pornografia snuff e a violência contra a mulher
}

A pornografia consumida nos dias de hoje é muito diferente daquela que se consumia nos anos 80, conforme Julie Bindel relata:

Há pessoas lendo isso que nunca encontraram pornografia extrema, e a maioria delas são mulheres. O tipo de pornografia agora disponível gratuitamente envolve engasgo, tapas e espancamentos e atos terrivelmente dolorosos, como penetrar em um orifício, como a boca, vagina ou ânus, com vários pênis e armas.

A pornografia que os meninos da minha escola viam no início dos anos 1970 é agora o que vemos na MTV. O material popular e facilmente acessível que posso 
encontrar online em segundos é muitas vezes sádico, brutal e misógino ao extremo. $(2018)^{2}$

Muito embora a existência de vídeos reais não tenha sido provada, Bindel relata a experiência por ela vivida:

Eu vi o tipo de pornografia que Madsen gostava. Na década de 1980, assisti a um snuff movie com outros ativistas anti-pornografia, jornalistas e especialistas em efeitos especiais de filmes. Um dos ativistas foi a uma loja de pornografia na Inglaterra e perguntou se o proprietário tinha algo "realmente extremo". O dono da loja deu a ela um filme de uma mulher na América do Sul sendo estuprada, torturada e assassinada. Vimos sua mão ser serrada enquanto ela ainda estava viva. Até mesmo os repórteres de crime endurecidos tiveram que deixar a sala para vomitar. As feministas ficaram. Sabíamos o que esperar, porque tínhamos ouvido falar sobre estupro de ativistas nos Estados Unidos que faziam campanha contra a tortura e o assassinato de mulheres para o prazer sexual dos homens.

Antes dessa exibição, muitos apologistas da pornografia alegaram que o estupro não existia e que as feministas, junto com os moralistas religiosos, o haviam inventado para dar peso às nossas campanhas anti-pornografia. Provamos que os céticos estavam errados. Os especialistas em filmes verificaram que não havia truques de câmera envolvidos. Um jornalista local escreveu sobre a exibição e pediu à polícia que tome medidas. Eles não o fizeram. $(2018)^{3}$

Se esse tipo de filme já era consumido em meados dos anos 80, imagine nos dias de hoje, quando está a um clique de distância. A questão não é só o consumo de pornografia, mas a maneira como a pornografia pode influenciar no comportamento sexual e na forma como as mulheres serão tratadas por esses homens que, o tempo todo, são incentivados, não só pela pornografia, mas também pela sociedade, a afirmar a superioridade masculina.

Gouvea discorre sobre o assunto:

\footnotetext{
2 There are people reading this who have never encountered extreme pornography, and most of them will be women. The kind of porn now available for free involves gagging, choking, slapping and beating, and horrendously painful acts such as penetrating an orifice, such as a mouth, vagina or anus, with multiple penises and weapons The porn that the boys at my school would look at in the early 1970s is now what we see on MTV. The mainstream, easily accessible stuff I can find online within seconds is often sadistic, brutal, and misogynistic in the extreme.(2018)

3 I have seen the type of porn that Madsen enjoyed. In the 1980s I watched a snuff movie with other anti-porn activists, journalists and experts in special film effects. One of the activists had gone into a porn shop in England and asked if the owner had something "really extreme". The storeowner gave her a film of a woman in South America being raped, tortured and murdered. We saw her hand sawn off while she was still alive. Even the hardened crime reporters had to leave the room to be sick. The feminists stayed. We knew what to expect, because we had heard about snuff from activists in the US who were campaigning against the torture and murder of women for men's sexual pleasure.

Prior to this viewing, many porn apologists claimed that snuff did not exist, and that feminists, along with religious moralists, had invented it in order to add weight to our anti-porn campaigns. We proved the sceptics wrong. The film experts verified that there were no camera tricks involved. A local journalist wrote about the screening, and urged police to take action. They did not.(2018)
} 
Eles são socializados para reafirmar masculinidade desesperadamente, a todo custo, para o resto da vida, e o que seria mais másculo que sexo e violência? Enquanto isso, as meninas seguem sendo socializadas para os mesmos desejos de aprovação masculina, os de sempre. Assim, enquanto os adolescentes do sexo masculino fazem pesquisas cada vez mais violentas no PornHub buscando satisfazer um narcisismo, meninas pensam, muito antes de descobrir a masturbação, em como podem se tornar atraentes para os homens, e acreditam que é ai que reside seu prazer.(2020)

Em contraponto, conforme Gouvea afirma, a mulher é educada para se submeter às vontades masculinas, tanto na ficção, quanto fora dela. A autora destaca a maneira como as mulheres são degradadas dentro da pornografia que sempre trata do prazer masculino:

Assim, elas descobrem o BDSM, a sexualidade passiva, e outros termos eufemizados que levam mulheres a práticas de autodestruição durante o sexo, estejam elas performando o sadismo ou o masoquismo, não importa, são os desejos masculinos que são levados em consideração.

Andrea Dworkin diz que "o sadismo sexual efetiva a identidade masculina. Mulheres são torturadas, chicoteadas, e acorrentadas; mulheres são amarradas e amordaçadas, marcadas e queimadas, cortadas com facas e fios; mulheres são urinadas e defecadas", dentre outras descrições que não vou reproduzir aqui, pois pode ferir muitas vítimas de violência, - e tudo isto para estabelecer no macho um sentido viável de seu valor próprio". É tudo sobre eles. (2020)

É nítido que a pornografia é produzida para os homens e, dentro desse mundo, existem subcategorias em que apenas o sexo consensual (mesmo que violento) não é suficiente. E é aí que entra o Snuff movie, definido por Matheus Ferraz, em seu artigo Snuff movies: Onde a vida é barata, como:

A palavra inglesa snuff tem a ver com o ato de se soprar uma vela e extinguir a sua chama. A palavra vem sido utilizada como gíria por séculos para falar de morte, e hoje está indelevelmente associada aos snuff movies, filmes onde pessoas são mortas de verdade em frente às câmeras. Essas produções feitas à surdina e comercializadas no mercado negro da pornografia (e, mais recentemente, na deep web) causam fascínio e medo nos fãs do horror, mesmo que sua existência ainda não tenha sido comprovada.

A expressão snuff movie foi cunhada no livro The Family: The Story of Charles Manson's Dune Buggy Attack Battalio, de Ed Sanders, onde ele afirma que a Família Manson produzia esse tipo de filme. Numa entrevista reproduzida no livro, um membro anônimo da Família fala sobre uma gravação onde "(...) uma moça jovem de uns 27 anos, cabelo curto... isso... e cortavam a cabeça dela fora”. Esse mesmo anônimo é quem usa pela primeira vez a palavra snuff nesse contexto. (2014)

Esse tipo de violência contra a mulher também está presente nas páginas de Mulheres

\section{Empilhadas:}

- Eu acreditava que pornografia era aquela coisa de cu e xoxota para homem broxa, mas você não tem ideia do que a Denise me mandou ler. Já ouviu falar numas merdas chamadas snuff? Cacete! Sabe o que é o cara matar a mulher, arrancar o útero dela e ejacular? O cara ejacula segurando nosso útero!

- Porra, Bia, são oito da manhã... 
- Ainda ontem eu achava que criticar pornografia era sacanear a liberdade de expressão... mas o cara ejacula...

- Bia!

- ...no nosso útero extirpado! (MELO, 2019, p.27)

Diante desse tipo de pornografia e seu consumo, a protagonista ainda destaca o fato de que também pode servir como forma de incentivar a violência contra a mulher:

- Você tem aí crimes que envolvam desmembramento, mutilação ou evisceração de mulheres?

- Vou vomitar ali e já respondo - falei.

- É a Denise quem está perguntando. Ela está planejando um capítulo sobre pornografia como gatilho para a matança de mulheres. (2019, p.27)

Sobre isso, é possível questionar até que ponto os snuffs movies podem influenciar os comportamentos masculinos em suas práticas sexuais e também aumentar os índices de violência contra a mulher.

Em 2017, Peter Madsen foi acusado de matar, desmembrar e estuprar a jornalista Kim Wall. E, durante as investigações, a polícia encontrou em seu computador referências aos snuff movies, conforme mostraram reportagens em jornais da época. A acusação teve certeza de que os vídeos assistidos por Madsen influenciaram na maneira como ele assassinou a jornalista, o que é corroborado por Bindel:

\begin{abstract}
Ao longo do julgamento, os promotores apresentaram evidências irrefutáveis do uso prolífico de pornografia violenta por Madsen. A polícia descobriu um disco rígido na oficina de Madsen que incluía filmes de estupro de mulheres sendo decapitadas, torturadas e empaladas em estacas de metal. O motivo de Madsen, disseram os promotores, foi que o assassino buscou prazer sexual com a morte e tortura de mulheres. O júri aceitou que foi isso o que aconteceu, e a sentença da juíza - vida sem possibilidade de liberdade condicional - sugere que ela também. $(2018)^{4}$
\end{abstract}

E a autora segue afirmando que grande parte dos homens que consomem esse tipo de pornografia sabe que as mulheres sofrem violência real:

Madsen e outros homens que consomem pornografia de tortura sabem que, para acessá-lo, mulheres são estupradas, abusadas, feridas e às vezes até mortas. Mulheres reais. As mulheres que sobrevivem têm que viver com o conhecimento de que um

4 Throughout the trial, prosecutors presented irrefutable evidence of Madsen's prolific use of violent pornography. Police discovered a hard drive in Madsen's workshop that included snuff films of women being beheaded, tortured and impaled on metal spikes. Madsen's motive, said the prosecutors, was that the killer sought sexual pleasure from the death and torture of women. The jury accepted that this is what had happened, and the judge's sentence - life without the possibility of parole - suggests that she did too. (2018) 
registro do abuso existirá muito depois de sua morte, e que os homens estarão se masturbando para sua dor e humilhação. $(2018)^{5}$

Bindel encerra o artigo dizendo que sem a misoginia, a pornografia não existiria. E, assim, a mulher não seria colocada em uma posição subalterna e não sofreria com a violência que também é incitada pelos filmes pornôs:

Sem misoginia, a pornografia não existiria. A pornografia que alimentou e validou as fantasias sádicas de Madsen é criada abusando das mulheres diante das câmeras. Negar que assistir constantemente à tortura de mulheres por prazer sexual não tem efeito material e não leva os homens a buscarem "experimentar" as cenas que assistem online é tão ilógico quanto alegar que publicidade de qualquer tipo não funciona.

Precisamos aceitar que a pornografia legitima a horrível degradação sexual das mulheres e que não serve a nenhum propósito, exceto vincular a violência e o abuso ao sexo nas mentes de meninos e homens. Kim Wall é vítima de Peter Madsen e da pornografia. $(2018)^{6}$

Gouvea também fala sobre o assunto:

(...) movimentos e posições pioneirizados pela pornografia são imitados. Segundo Naomi Wolf, em $O$ Mito da Beleza, quando fala sobre a influência da mídia pornificada nos ideais de feminilidade, a pornografia foi ficando cada vez mais violenta porque, aos poucos, imagens que mostravam o sexo da forma que ele é foram ficando desinteressantes para os espectadores. Assim, com o crescimento dessa indústria, as fantasias masculinas mais agressivas passaram a ser reproduzidas.

Fantasias como o famoso e absurdo "rape play", bondage, spank. Fetiches envolvendo incesto, menininhas inocentes saindo do colégio ou donas de casa desesperadas. Pessoas reais supostamente encenando estupro e até pedofilia. (2020)

É possível notar, mais uma vez, a ligação entre as páginas escritas por Patrícia Melo e a realidade brasileira. Por isso, fica claro que, assim como em Mulheres Empilhadas, os homens realmente podem ser influenciados pela pornografia na forma como tratam as mulheres, até ceifando-lhes a vida, como a da jornalista Kim Wall.

A leitura de Mulheres Empilhadas pode gerar inquietação no leitor pela maneira crua com que a violência é narrada e como o silêncio das mulheres leva a uma reflexão da

5 Madsen and other men who consume torture porn know that in order for them to access it, women are raped, abused, hurt and sometimes even killed. Real women. The women who survive have to live with the knowledge that a record of the abuse will exist long after they are dead, and that men will be masturbating to their pain and humiliation. (2018)

6 Without misogyny, porn would not exist. The porn that fuelled and validated Madsen's sadistic fantasies is created by abusing women on camera. To deny that constantly viewing the torture of women for sexual pleasure has no material effect and does not lead to men seeking to "try out" the scenes they view online is as illogical as claiming that advertising of any kind does not work.

We need to accept that pornography legitimises the horrific sexual debasement of women, and that it serves no purpose except to link violence and abuse with sex in the minds of boys and men. Kim Wall is a victim of Peter Madsen, and of pornography. (2018) 
representação literária da violência. O sofrimento das mulheres registrado todos os dias nos noticiários, somado às crescentes estatísticas, ao medo e à angústia foram o combustível para que a obra de Patrícia Melo surgisse.

O romance parece cumprir com o seu principal objetivo: denunciar a morte, o estupro e a agressão de mulheres no Brasil. E faz isso de forma que, durante toda a leitura, deixa claro que todos os casos fictícios retratados poderiam, claramente, acontecer na realidade, não brasileira, mas em qualquer local do mundo. E, diante desse quadro, é preciso que esse tipo de realidade não seja alimentado por mídia, livros, letras de música e, principalmente, pela pornografia, conforme Melo denúncia em sua obra.

Assim como a pornografia, a mídia e a música, a literatura também assume a sua parcela de culpa em casos de violência de gênero, uma vez que, ao romantizar relacionamentos abusivos, autores podem influenciar leitoras a aceitar alguns comportamentos como normais e tentarem trilhar um caminho que leve à redenção do agressor. O principal objetivo de uma literatura produzida para mulheres deveria ser emancipar a mulher que, após ser propriedade dos homens por tanto tempo, deseja ser dona de si mesma, conforme Locke, citado por Birman, afirma:

(...) o corpo é uma propriedade privada do indivíduo que o contém, de maneira que nenhum outro pode dele legalmente se apossar, do jeito que quiser e bem entender, sem a prévia autorização do seu dono. Fazer isso implicaria, pois, transgredir uma relação de propriedade, já que o corpo seria para a filosofia política de Locke a propriedade originária da individualidade, isto é, o seu território inicial de domínio sobre o mundo. (2009, p.177)

Portanto, quando se trata de Feminismo, é preciso que o mesmo também esteja presente em obras literárias, uma vez que a arte também tem seu papel como denunciante de problemas sociais, sendo a violência de gênero uma delas. Literatura feita por mulheres não é uma invenção recente. Nos séculos passados, mulheres já iam à luta por mais direitos e melhores condições de vida, já havia aquelas que procuravam ter voz apesar das letras. Entretanto, essas mulheres começaram a ter mais voz a partir da segunda metade do século XX, conforma Vianna mostra no trecho abaixo:

A irmandade feminina/feminista emergiu no texto das mulheres mais decididamente nos anos 60/70, pleiteando direitos no mundo público, deflagrando um processo de afirmação identitária que permanece avançando e tem como um dos seus espaços de combate a linguagem, lugar onde o conhecimento sobre nós mesmas se realiza e onde a subjetividade é construída. Ao multiplicarem-se o número de publicações de textos 
escritos por mulheres, multiplicam-se as possibilidades de conhecimento sobre as diferentes perspectivas pelas quais elas se dão a conhecer no mundo. (2019)

Se a mulher se vê representada na literatura, o mesmo quase não acontece na pornografia. Filmes pornôs não são feitos para mulheres. Tem-se como exemplo uma série brasileira, exibida pelo canal HBO, em 2020, chamada Hard, homônima de uma série francesa, exibida entre 2008 e 2015. Nessa série, Sofia é uma socialite que abandonou a carreira de advogada para se dedicar à família. Seu marido morre e ela descobre que ele tinha uma vida dupla e sua herança é uma produtora de filmes pornográficos. Relutante, Sofia assume o negócio para que possa sustentar a sua família. E, a partir de então, ela não só descortina o olhar extremamente machista da indústria de entretenimento adulto, mas tenta subvertê-lo. Lúcio de Oliveira disserta sobre isso:

Hard coloca no centro da cena o choque cultural. Obrigada a deixar os antigos preconceitos de lado, Sofia descobrirá o mundo de SofiX criado pelo seu marido e assumirá a missão de modernizar a produtora para filmar pornografia de qualidade, que também seja consumida por mulheres. (2020)

Entretanto, essas mudanças sutis não alteram o fato de que a pornografia tem uma relação de causa e consequência quando se trata de violência contra a mulher, servindo como gatilho para a matança, pois, o homem, ao consumir pornografia tem a ideia de que a forma como o sexo é retratado é a maneira correta de fazer a mulher sentir prazer. Soma-se a isso a pornografia snuff, em que o homem sente prazer ao ver a mulher sentir dor ou, até mesmo, ser morta. Nesse tipo de filme, o sexo é usado para disciplinar e subjugar. E, saindo da indústria pornográfica, mas se mantendo no campo da violência de gênero, encontra-se o porn revenge (pornografia de vingança), pois, quando a mulher não se submete, vídeos ou fotos íntimas são usadas como forma de puni-la e degradá-la diante da sociedade.

$\mathrm{Na}$ atualidade, com o advento da internet, em que tudo está a um clique de distância, torna-se claro que o ambiente cibernético fez com que a violência contra a mulher passasse por um processo de ressignificação, uma vez que a mulher não sofre violência física, mas o ato não diminui o peso da violência sofria, principalmente aquela não percebida, como assédio transmutado em elogios e ciúme exacerbado disfarçado de cuidado. Tem-se o que Pierre Bourdieu chama de violência simbólica:

Sempre vi na dominação masculina e no modo como é imposta e vivenciada, o exemplo por excelência (...) (da) submissão paradoxal, resultante daquilo que eu chamo de violência simbólica, violência suave, insensível a suas próprias vítimas, que se exerce essencialmente pelas vias (...)simbólicas da comunicação e do conhecimento, ou, mais precisamente, do desconhecimento, do reconhecimento, ou, em última instância, do sentimento. (2007, p. 7) 
A violência simbólica sofrida por muitas mulheres acontece de forma sutil. A protagonista de Mulheres Empilhadas é uma vítima desse tipo de violência logo no começo do livro a partir do momento em que Amir começa a tentar controlar a sua vida, desmerece a sua inteligência e critica algumas coisas em que a jovem acredita. Porém, a violência deixa de ser psicológica, para tornar-se física e, depois, moral, pois a jovem não se deixa dominar.

A obra leva a uma reflexão sobre a situação da mulher na contemporaneidade; que, mesmo com as conquistas ao longo dos anos, permanece lutando por direitos e equidade perante os homens. A dominação masculina não será mais aceita. Segundo Rosiska Darcy de Oliveira:

\begin{abstract}
Essa cultura masculina alimentou representações das mulheres como seres anfíbios, mais instintuais que os homens: alheias à Razão, rebeldes à domesticação, como se, nelas, a Natureza guardasse seus direitos de permanência, de imutabilidade, de regularidade. Naturalizadas, as mulheres não foram incorporadas ou tornadas significativas na cultura humana/masculina. O confinamento do sexo feminino em uma relação limitada com apenas alguns aspectos do meio ambiente, fruto da diferenciação sexual, traduziu-se em desigualdade de status e poder, tornando-se hierarquia que, por seu caráter invariante, passou a ser percebida como um dado do comportamento humano, inscrita no corpo e por ele ditado, e que as representações mitológicas e ideológicas só fizeram confirmar (1999, p. 40).
\end{abstract}

Enquanto os homens construíam a história, as mulheres aguardavam. E, quando decidiram ocupar espaços que muitos julgavam inapropriados e passaram a denunciar a violência que sofriam, a punição tornou-se ainda mais severa, extrapolando o mundo real e atingindo o virtual, por isso, Patrícia Melo procura desconstruir essa imagem e colocar em xeque a ideia de que o lugar da mulher é em casa a partir do momento em que suas personagens assumem funções que, durante muito tempo, foram vistas como masculinas (advogado, promotor etc.). Dessa forma, Melo produz uma literatura que, de certa maneira, tem um papel militante, pois coloca o leitor como alguém que pode mudar através da literatura, conforme Carlos Erivany Fantinati deixa claro, já que “(...) um aliado potencial a ser convertido e transformado, pela elevação do seu nível de consciência, em coadjuvante no processo de mudança social (...) realizar uma obra que contenha um sentido revolucionário do ponto de vista social." (2012, p. 3- 4)

Afinal, para além de entreter, a literatura pode levar ao crescimento pessoal e promover reflexões, o que serviu de mote para o desenvolvimento dessa desse ensaio. Ao dar voz e destaque às personagens femininas, Patrícia Melo não apenas evidencia a violência de gênero, mas também escancara os problemas do sistema judiciário brasileiro que ainda é alicerçado no patriarcalismo. 
Casos recentes como da digital influencer Mariana Ferrer, que foi dopada e estuprada em uma casa noturna catarinense, deixam isso muito claro. Mesmo com provas de que foi dopada e com material genético do estuprador, o agressor foi inocentado por falta de material. E, mais uma vez, a internet foi usada como forma de subjugar a mulher, pois a Justiça silenciou Mariana em suas redes sociais, proibindo-a de falar sobre o caso. E aina houve mais, pois, durante uma audiência online, no dia em que o acusado foi absolvido, Mariana ainda foi agredida verbalmente pelo advogado de defesa, que a acusou de facilitar o sexo sem consentimento, expondo fotos da vítima de biquíni e em poses sensuais (retiradas de suas redes sociais e manipuladas), como se aquilo justificasse o ato do seu cliente que não pode resistir aos encantos da moça. Foi, assim, que nasceu a tese do estupro culposo, ou seja, quando se estupra sem a intenção de cometer o crime.

O ocorrido com Mariana Ferrer causou grande comoção nas redes sociais e poderia, perfeitamente, ser um dos casos narrados em Mulheres Empilhadas que, embora seja uma narrativa ficcional, busca uma aproximação com a realidade pela abordagem de diferentes formas de violência sofridas por mulheres em seu enredo, também explora a desumanização dos personagens como forma de despertar no leitor uma reflexão sobre o cenário de violência.

\section{Conclusão}

A partir da escolha do corpus deste ensaio, observa-se que discutir sobre a violência contra a mulher, em Mulheres Empilhadas, torna-se mais eficiente quando se fala sobre o assunto através de uma ótica feminina, não só da narradora da obra, mas também em sua autoria. Entretanto, é necessário que isso seja feito de forma responsável, pois conteúdos produzidos de forma leviana pela mídia, arte e imprensa propagam e retroalimentam o sentimento misógino em todas as esferas da sociedade. Reside aí a necessidade de se escrever e produzir matérias que abordem a temática de forma crítica e responsável, pois, se assim não se fizer, não haverá qualquer modificação no circuito de músicas, livros e filmes que incentivam e naturalizam comportamentos machistas.

Ao escolher não nomear sua protagonista, a do romance mostra a anulação diante da sociedade a que várias mulheres são submetidas, ao passo que os nomes de mulheres assassinadas que iniciam os capítulos mostram que o texto literário aborda um problema real que não deve cair no esquecimento quando o leitor termina o livro. Por isso, Mulheres Empilhadas pode ser considerado um romance-denúncia. 
Este ensaio pretendeu apresentar breve análise de uma obra contemporânea, cuja qualidade literária e coragem em tratar de assuntos referentes às políticas de enfrentamento de um problema social tão grave quanto à violência de gênero servem de suporte para construção de um lugar para as mulheres silenciadas; uma narrativa que procura desvendar o novo cenário da representação da violência de gênero na literatura contemporânea brasileira, dando destaque à violência cibernética.

Se, durante muito tempo, a violência de gênero apenas transformava as mulheres em números estatísticos, o sentido da obra de Patrícia Melo está ligado ao ato de lembrar, dar voz às mulheres e não as deixar cair no limbo dos números, rompendo, assim, com a parca exploração que o tema tem na literatura brasileira da atualidade.

\section{Referências}

BENHABIB, Seyla e CORNELL, Drucila (org,). Feminismo como crítica da modernidade. Rio de Janeiro: Rosa dos Ventos, 1987.

BINDEL, Julie. I've seen the type of violent snuff porn Peter Madsen viewed before he murdered Kim Wall - anyone who denies a connection is deluded. 2018. Disponível em: https://www.independent.co.uk/voices/kim-wall-peter-madsen-snuff-porn-submarine-inventorsubmarine-swedish-journalist-a8322076.html Acessado em: 19/01/2021.

BIRMAN, Joel. Cartografias do feminino. São Paulo: Editora 34, 2009.

BOURDIEU, Pierre. A dominação masculina. Trad. Maria Helena Kühner. 5 ed. Rio de Janeiro: Bertrand Brasil, 2007.

BUZZI, Vitória de Macedo. Pornografia de vingança: contexto histórico-social e a abordagem no direito brasileiro. 2015. 111 f. Monografia (Graduação em Direito) - Centro de Ciências Jurídicas, Universidade Federal de Santa Catarina, Florianópolis, 2015. Disponível em: https://repositorio.ufsc.br/xmlui/bitstream/handle/123456789/133841/TCC\%20Vit\%c3\%b3ria\%20Buz zi\%20Versao\%20Repositorio.pdf?sequence=1\&isAllowed=y Acessado em: 18/01/2021.

FANTINATI, Carlos Erivany. O Profeta e o Escrivão: Estudo sobre Lima Barreto. São Paulo: UNESP, 2012.

FERRAZ, Matheus. Snuff movies: onde a vida é barata. 2014. Disponível em: https://bocadoinferno.com.br/artigos/2014/06/snuff-movies-onde-a-vida-e-barata/ Acessado em: 19/01/2021.

GOUVEA, Natália. Pornografia, cultura do estupro e a violência nas relações. 2020. Disponível em: https://qgfeminista.org/pornografia-cultura-do-estupro-e-a-violencia-nasrelacoes/ Acessado em: 19/01/2021. 
LEI $\quad \mathrm{N}^{\mathrm{o}}$ 13.718. Disponível em: http://www.planalto.gov.br/ccivil 03/_ato20152018/2018/lei/L13718.htm Acessado em: 18/01/2021.

MELO, Patrícia. Mulheres Empilhadas. São Paulo: LeYa, 2019.

PRAVAZ, Suzana. Três estilos de mulher: a doméstica, a sensual, a combativa. São Paulo: Paz e Terra, 1981.

OLIVEIRA, Lúcio de. Hard - a mudança de uma era por meio da comédia. 2020. Disponível em: https://pipocasclub.com.br/2020/06/19/hard-mudanca-era-por-meio-comedia/ Acessado em: 31/05/2021.

OLIVEIRA, Rosiska Darcy de. Elogio da diferença: o feminino emergente. São Paulo: Brasiliense, 1999. SAFFIOTI, Heleieth I. B. "Já se mete a colher em briga de marido e mulher”. In: São Paulo em perspectiva. São Paulo: Fundação Seade, v. 13, n. 4, oct./dec. 1999, pp. 82-91. Disponível em: https://www.scielo.br/j/spp/a/qKKQXTJ3kQm3D5QMTY5PQqw/?lang=pt\&format=pdf Acessado em $31 / 05 / 2021$.

VIANNA, Lúcia Helena. Poética feminista - poética da memória. 2019. Disponível em: https://medium.com/revistalabrys/po\%C3\%A9tica-feminista-po\%C3\%A9tica-damem\%C3\%B3ria-b53c2a6c58df Acessado em: 31/05/2021.

Recebido em 30 de janeiro de 2021 Aceito em 04 de junho de 2021 